\title{
Additional Improvements to the NASA Lewis Ice Accretion Code LEWICE
}

\author{
William B. Wright \\ NYMA, Inc. \\ Brook Park, $\mathrm{OH}$ \\ Colin S. Bidwell
NASA Lewis
Cleveland, OH
}

Abstract

Due to the feed back of the user community, three major features have been added to the NASA Lewis ice accretion code LEWICE. These features include: first, further improvements to the numerics of the code so that more time steps can be run and so that the code is more stable; second, inclusion and refinement of the roughness prediction model described in an eartier paper; third, inclusion of multielement trajectory and ice accretion capabilities to LEWICE. This paper will describe each of these advancements in full and make comparisons with the experimental data available. Further refinement of these features and inclusion of additional features will be performed as more feedback is received.

\footnotetext{
Nomenclature

$b=$ bead height/roughness $(m)$

$F=$ wetness fraction

$V=$ velocity $(\mathrm{m} / \mathrm{s})$

$s=$ surface distance $(m)$

$r=$ water density

$\mathrm{s}=$ surface tension $(\mathrm{kg} / \mathrm{m} / \mathrm{s})$
}

\section{Introduction}

Three major features have been added to the NASA Lewis ice accretion code LEWICE. ${ }^{1}$ The numerics have been improved, the roughness prediction model has been revised, and a multi-element capability has been added.

The numerics of the code have been improved in several ways to produce more accurate ice shapes. The convergence characteristics of the code have been improved by implementing an adaptive grid technique, a new ice growth algorithm and a new variable time stepping scheme. Improvements to the transition model and transition heat transfer calculations have been made to produce more realistic results. New additions include a "pseudo" surface which produces more realistic heat transfer for large glaze ice shapes and a mass addition routine which allows ice growth in arbitrary directions.

An adaptive grid scheme has been implemented, which allows more optimal tailoring of the individual surface models for each phase of the ice growth process yielding smoother more accurate ice shapes, better convergence characteristics and quicker run times. A highty refined "baseline" model is used to represent the geometry at each time step. This model is updated after each time step.

Adaptive griding techniques are used to generate optimal surface models from the baseline model for the heat transfer, the collection efficiency, mass bal- 
ance, energy balance, and the mass addition phases. A typical baseline model may contain 4000 points. A typical flow panel model for accurate trajectory calculation may have constant leading edge spacing and require 100 points. Flow panel models used for the generation of velocities for the heat transfer coefficient calculation, which can be either of the "pseudo" surface type (which produces more realistic heat transfer for glaze shapes) or keyed to radius of curvature, may typically require 150 panels. A typical surface model for the energy balance, the mass balance and mass addition algorithms may contain several thousand points.

A new ice growth scheme has been implemented. This scheme employs a separate time stepping procedure on a highly refined surface model. The method features local conservation of mass, accurate resolution of complex ice shapes, and eradication of the troublesome problem of iced lobes growing into each other.

The time stepping procedure has been automated. The user specifies the maximum ice thickness to be added at each time step. The time step is varied at each time step to match this maximum amount of ice thickness. This ice growth scheme yields better convergence characteristics by giving the user more precise control over the maximum geometric change and hence aerodynamic change between consecutive time steps.

Additional improvements include improvements to the transition model, the transition heat transfer calculation, incorporation of a more realistic "pseudo" surface and additions to the ice growth module. The transition model has been modified to produce more realistic transition locations for cases with large or multiple stagnation points. A more realistic treatment of the laminar and turbulent heat transfer coefficient in the transition region has been implemented. The new ice growth model allows ice growth in abitrary directions to accommodate current and future ice growth models. An optional "pseudo" surface method has been installed which more accurately models flow and hence heat transfer for ice shapes with large stagnation zones.

The roughness prediction model used is the same model that was described in a previous paper. ${ }^{2}$ Previously, this model was not considered reliable due to the deteriorating accuracy of the code for multiple time steps. Due to the increased accuracy of the code for multiple time steps, this routine was reactivated. Comparisons will be made between this model and the measured roughness heights obtained by Shin. $^{3}$ This routine is considered reliable enough that the standard input of sand-grain roughness into LEWICE has been removed.

The third feature is the addition of multi-element capability to LEWICE. The potential flow solver has always been capable of producing multi-element flows, but only now have the trajectory, energy balance and ice addition routines been correctly modified to produce multi-element ice accretions. A comparison will be made with experimental data obtained in the IRT.4

Since several versions of the LEWICE code are being used by industry, the next section will provide a short history of LEWICE along with the current nomenclature of the codes. Results from the modifications will then be presented.

\section{LEWICE History}

In 1983, as a result of university grants and inhouse research at the NASA Lewis Research Center, three computer codes were developed: a potential flow code, a droplet trajectory code, and an energy balance code. This combined effort, which was called LEWICE, was used exclusivety for in-house research at Lewis. In current nomenclature, this will be called LEWICE version 0.1.

Through funding by FAA and NASA Lewis, in 1987 the previous codes were combined into a form usable by industry and distribution began. This version will be called LEWICE 0.5 .

Through additional funding by NASA Lewis, interactive graphics capabilities were added and a correlation for surface roughness were added. The code's capabilities and usefulness were documented in CR 185129, Users Manual for the NASA Lewis Ice Accretion Code, LEWICE. This version will be called LEWICE 1.0

As usage of the code increased, both in industry and at NASA Lewis, several errors were detected and fixed in the code and several new features were added. These new capabilities were documented in a previous AIAA paper ${ }^{2}$ and a NASA Contractor Report. ${ }^{5}$ This version was initially released in June 
1993 as LEWICE Beta, and will be called LEWICE 1.3 in current nomenclature.

The code described in this paper is the first update to LEWICE since that time. It is available for limited release. Users of this code, which will be called LEWICE 1.6, are advised that it is still under development and may contain several bugs which have not yet surfaced. Users who request version 1.6 will be asked to promptly report problems they have with the code and to provide to NASA the input files for these problem cases.

Future plans for LEWICE upgrades include a new roughness model and new heat transfer model, both based on experimental data. A new Users Manual will be produced for that code instead of the current updates. Current nomenclature will refer to this future code as LEWICE 2.0

\section{Numerical Improvements}

Several improvements were made to the LEWICE code which allow for more accurate ice shape predictions. These include changes to the surface modeling, mass addition and time stepping algorithm to improve convergence characteristics of LEWICE. Modifications were also made to the transition model, the calculation of transition heat transfer transition heat models to produce more realistic heat transfer. New additions include an ice growth algorithm which allows ice growth in arbitrary directions and a new "pseudo" surface which features improve heat transfer prediction for large glaze shapes.

Several changes to the LEWICE calculation scheme have been made to achieve good convergence characteristics. A converged sotution is one that ceases to change with increasing size and or increased number of time steps. Any good numerical method should have good convergence characteristics. Convergence is generally controlled by increas. ing the number of grid points or time steps within the accuracy of the computer.

For LEWICE, convergence is measured using ice shapes and is controlled by the number of time steps and grid points. Convergence has occurred when an increase in time steps or grid points results in no appreciable change in the ice shape. LEWICE has had a history of poor convergence characteristics. The complex, nonlinear nature of ice growth has been a severe impediment in producing conver- gence. The number of possible time steps have been limited to 5 steps for some complex glaze shapes and 10 steps for some simple rime shapes. After these limits flow code failure and ice shape divergence were common. These changes have been made to LEWICE to overcome the problems resulting in poor convergence and cases have been run using as many as 1000 time steps.

An adaptive grid technique was incorporated into LEWICE to allow optimization for each phase of the ice accretion process. Surface models are generated from a highly refined baseline model using adaptive grid techniques. Separate surface modeis can be used for each step in the ice accretion calculation depending on the specific accuracy requirements for that step. The adaptive grid method is useful in producing surface models with point distributions that are sufficiently dense in regions of interest, vary smoothly and have a minimum of points, insuring computational accuracy and speed. The adaptive grid technique involves the use of weighting functions supplied by the user to produce weighted point distributions for a surface. Surface models can be generated which resolve any variable of interest in the icing process. Weight functions can be chosen to produce densely packed points in regions of interest and sparsely packed points away from the region of interest. Possible weighting functions could include: radius of curvature, velocity or velocity gradient, collection efficiency or collection efficiency gradient, ice thickness or ice thickness gradient.

Currently three surface models with various options are used for the icing calculation. For the heat transfer calculation two types of models can be used: a standard surface model and a "pseudo" surface model. For both models, point distributions are weighted using radius of curvature with user specified constraints on maximum and minimum point spacing. For the trajectory calculation, surface point distributions are optionally weighted to collection efficiency or towards a constant leading edge spacing. The baseline model is used for the remaining mass balance, energy balance and the mass addition calculations. This model, which features several thousand equally spaced points, was found to be sufficiently accurate for these calculations and reduced the error in the task of updating the baseline model after each time step.

The ice growth scheme has been modified to produce more conservative, accurate, and smoother 
ice shapes. The scheme involves a separate time stepping procedure for the ice growth module. ice is added to the geometry in small increments to a highly refined surface model. During each ice addition step, the new surface model is checked for regions of convergence and divergence. Points in regions of high convergence are removed to keep the region from growing into itself. Points are added in regions of high divergence to preserve the resolution of the surface model. Step size is varied according to convergence and divergence rates of the surface model to produce a smooth ice shape. The ice addition routine continues, conserving mass locally, until all of the ice has been added for the current time step.

A new variable time stepping algorithm was installed which has better convergence characteristics, is more automated and is computationally more accurate and quicker then traditional constant time stepping algorithms. The new method involves restricting the maximum ice thickness for a given time step to a specified amount. Essentially the maximum allowable ice thickness is set and the time step is allowed to vary to produce this maximum thickness. A defautt value of $0.2 \%$ chord has been found to be reasonable, but this can be changed by the user.

This type of time stepping allows direct control over the most important parameter affecting convergence which is geometric change. Geometric change is the direct cause of change in both collection efficiency and heat transfer distribution which are the two main contributors to ice shape calculation. If the amount of geometric change can be controlled in a systematic way, then changes in collection efficiency and heat transfer distribution can be controlled as well and good convergence characteristics can be achieved.

This time stepping technique should be highly independent of both geometry and icing condition lending itself to automation. Simply put, if the maximum geometric change which produces a discernible change in collection and heat transfer is known, then this value can be set and should not have to be changed for any condition or configuration. The technique produces larger times steps for periods of small geometric growth and smaller time steps for periods of large geometric growth than the traditional methods, producing fewer and more accurate time steps.
The transition model has been modified to produce realistic transition for cases with multiple stagnation points. Previously it was possible for transition to be predicted prematurely for cases with multiple stagnation points. This resulted in poor heat transfer distributions where transition would be predicted very near the leading edge. This would cause the heat transfer coefficient aft of the transition point to be less than the laminar value. This shortcoming is responsible for a good portion of the ice shape asymmetry observed for seemingly symmetric glaze icing conditions (e.g. NACA-0012 at 0 degrees angle-ofattack). The transition model is highly dependent on velocity gradients, which are realistically large between multiple stagnation points. Transition was predicted prematurely between consecutive stagnation points because of these large gradients even though the velocities were near zero. The newly incorporated model forces transition to be delayed until aft of the aftmost stagnation point at the leading edge producing more realistic heat transfer. This correction provides the desired result of producing turbulent heat transfer coefficients which are higher than the laminar values, which is a more realistic result.

Corrections were made to the transition heat transfer calculation so that the boundary layer would not prematurely transition from laminar to turbulent. A premature transition occurs for high roughness values and causes the turbulent heat transfer coefficient downstream of transition to be lower than the laminar value. Transition is delayed in these cases until the computed turbulent heat transfer is greater than or equal to the laminar value at this location.

A new ice growth algorithm which allows specification of arbitrary ice growth directions has been implemented. Current options include growth directions in the surface normal direction, flow direction and in the trajectory tangent directions. This algorithm will allow easy incorporation of future ice growth models.

Finally, a new optional 'pseudo' surface has been implemented which produces more realistic heat transfer for cases with large stagnation zones than the previous model. It is known that imviscid codes do not produce realistic surface velocity distributions for large concave forward facing regions such as a large glaze ice shape. Surface velocity and surface velocity gradients are overpredicted resulting in poor heat transfer prediction. A more realistic flow solution can 
be obtained using the inviscid panel codes by filling in the large concave region, essentially modelling it as a forward facing flat plate. A method has been implemented which scans the surface model for voids and fills them.

As evidence of the improved capabilities this model provides, the following case was run. A 21 inch NACA0012 was run at $0^{\circ}$ angle of attack for 45 minutes using 10 second time steps, resulting in 270 time steps in the simulation. 10 seconds is smaller than the smallest time step used in the automated time step mode. The automated time step procedure used 83 time steps, an average of $\mathbf{3 2 . 5}$ seconds per time step.

Two conditions were run. Both had a velocity of $150 \mathrm{mph}$, liquid water content of $0.5 \mathrm{~g} / \mathrm{m}^{3}$, and a droplet diameter of 20 microns. The first case was a rime ice case with a total temperature of $-8{ }^{\circ} \mathrm{F}$ while the second case was a glaze ice case with a total temperature of $28^{\circ} \mathrm{F}$.

The final shape of the rime ice case is shown in Figure 1. Although experimental data is not taken for this long of an icing time, the mass, shape and maximum thickness are proportional to shorter cases ran in the IRT to which LEWICE has been compared. To demonstrate the high accuracy of the current model, the lower surface is reflected upwards to show the symmetry of this shape. This is shown in Figure 2. The symmetry of the ice is nearly perfect. It was unheard of to run the previous versions for more than 10 time steps, and even then accuracy of this level could not be obtained.

The glaze ice case, ran at a $28{ }^{\circ} \mathrm{F}$ total temperature, is shown in Figure 3. A 10 second time step was used for this case as well. Again, although experimental data is not available for this nu, the horn growth proceeds logically as time progresses. Previous versions of LEWICE could only be run accurately for 5 or 6 time steps in glaze conditions, yet this version can easily handle 270 time steps with such large horns. Again, the lower surface is reflected upwards to show the symmetry of the solution. This result is shown in Figure 4.

The symmetry achieved numerically far exceeds the symmetry available experimentally for much shorter icing times. The difference between the upper and lower horn angles is $0.7^{\circ}$ and the difference in horn length is $2 \mathrm{~mm}$ ( $4 \%$ of length). The symmetry achieved here shows that each module is being exe- cuted accurately. If any of the modules is not being performed correctly, then the shape would not be symmetric. This result provides confidence that the ice shape is being computed accurately for other cases.

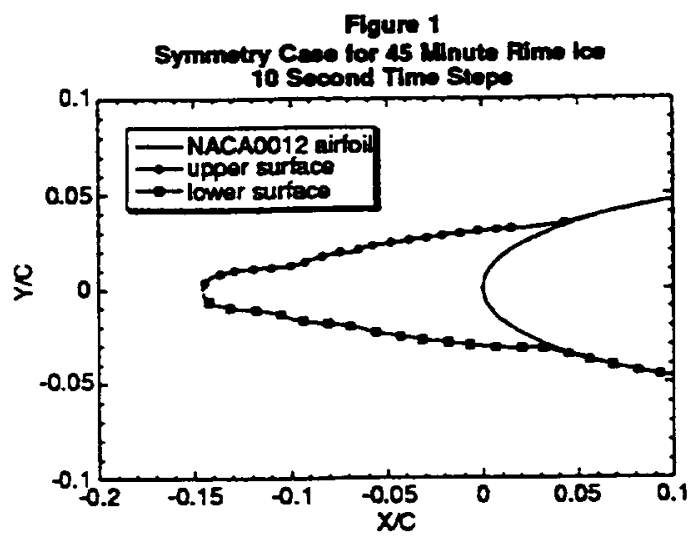

Figure 2

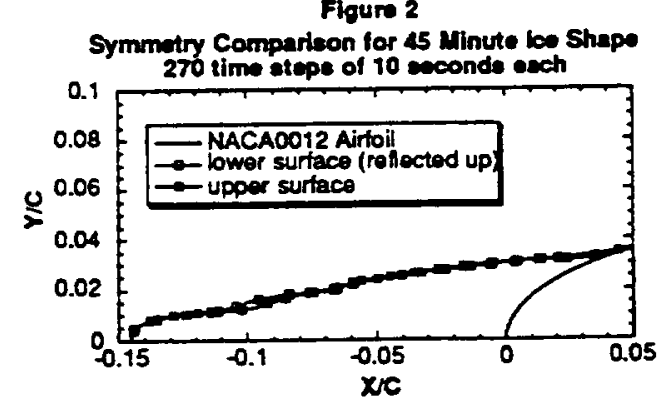

Figure 3

Symmetry coes of 45 Minute Ginze lce

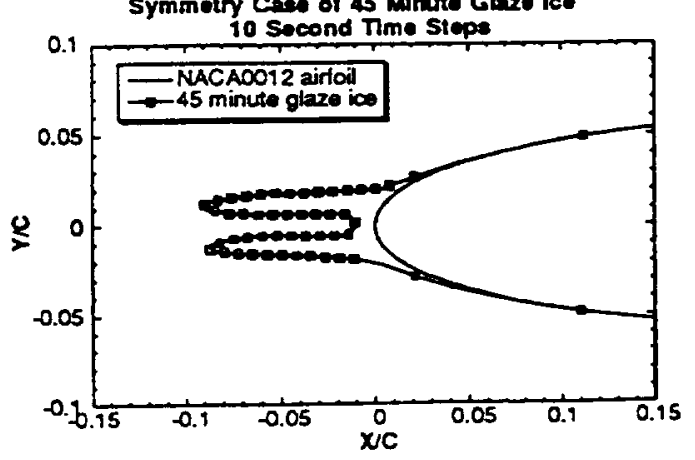




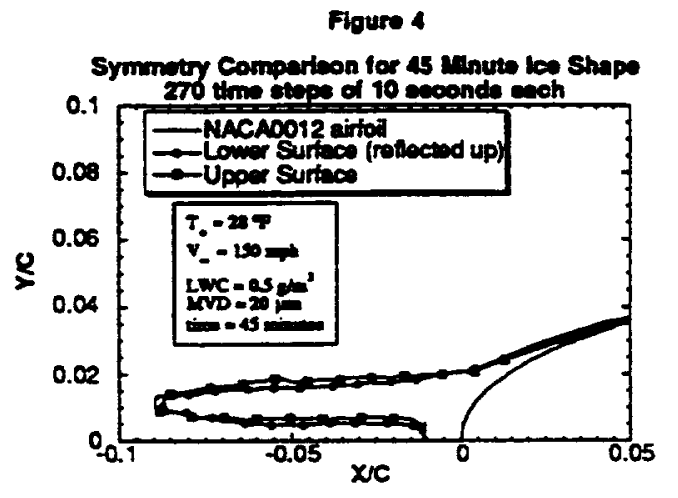

Roughness Prediction

The model used for predicting the distribution of roughness on an airfoil was developed in a previous paper, therefore a detailed derivation will not be presented. The height of roughness is determined by equating the force of the water flow with the force caused by surface tension. The runback model used to arrive at these forces was developed by Al-Khalii. ${ }^{6}$

The advantages of this model are that it produces results which qualitatively agree with measured roughness data and that it relieves the burden on the user of having to input a crucial parameter for glaze ice. The disadvantage of the current model is that it does not predict some of the trends shown by the measured roughness data. The equation for the local height of roughness is

$$
b=\left(\frac{4 \sigma}{\rho\left(F \frac{d}{d s} V\right)^{2}}\right)^{\frac{1}{3}}
$$

where the upper bound on this height is the local height of the ice shape. The use of this upper bound shows the first discrepancy in the experimental data. The measured roughness reached a stable height after two minutes and did not increase thereatter, whereas the predicted roughness will continue to increase.
An example of the roughness distribution obtained by this method is shown in Figure 5. The conditions represent the 'baseline' case used by $\mathrm{Shin}^{3}$ in his IRT test. His measured data is represented by the squares. The size of the squares represents the margin of error in the data.

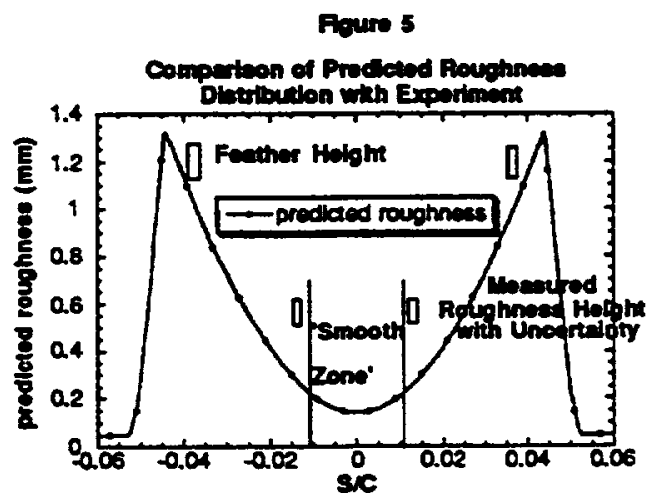

In that effort, he reported a 'smooth' zone near the leading edge, followed by a region of uniform roughness. This is qualitatively represented in the model, although the predicted distribution does not show an abrupt change in height. Shin then reports a feather height, which is also shown in this plot.

Despite the agreement of the roughness distribution, the distribution itself is not used in the code due to the numerical inaccuracy of the flow derivative. After several time steps, the quality of the solution decreases significantly if the distribution is used. Instead, an average roughness is used in the code. The equation for this is

$$
b_{\text {evg }}=\frac{\int_{0}^{s} b_{i} d s}{\int_{0}^{s} d s}
$$

This average roughness is then used as the sand-grain roughness for the entire airfoil. This average value is amazingly close to the measured roughness values found in Shin's experiment. In the test, parameterizations of LWC, velocity, temperature and time were performed to establish the variation of roughness with these parameters. The tests were 
conducted on a 21" chord NACA0012 at $0^{\circ}$ angle of attack. The matrix centered around these conditions:

$$
\begin{aligned}
& L W C=0.5 \mathrm{~g} / \mathrm{m}^{3} \\
& V=150 \mathrm{mph} \\
& T=28{ }^{\circ} \mathrm{F} \\
& M V D=20 \mu \mathrm{m} \\
& \text { time }=6 \mathrm{~min} .
\end{aligned}
$$

The parameterization used three velocities (150, $200,250 \mathrm{mph})$, three temperatures $\left(25,28,30^{\circ} \mathrm{F}\right)$, four LWC's $\left(0.5,0.75,1.0,1.2 \mathrm{~g} / \mathrm{m}^{3}\right)$ and four times (1, 2, 3, 6 minutes).

The first case shows the increase in roughness with icing time and is shown in Figure 6. For this plot, the experimental data is shown as solid squares with error bars. These error bars are $0.06 \mathrm{~mm}$ and represent an estimate by Shin of the error in the measuring technique. He also reported errors for each individual measurement, but it was more convenient to show a single error level for all measurements. The model predicts the level of roughness, although the increase with time is more gradual in the predicted values. It also continues to increase with time, whereas the experimental data shows no significant increase in roughness past 2 minutes. However, it is an improvement over previous models which had no variation in roughness with time:

Figure 6

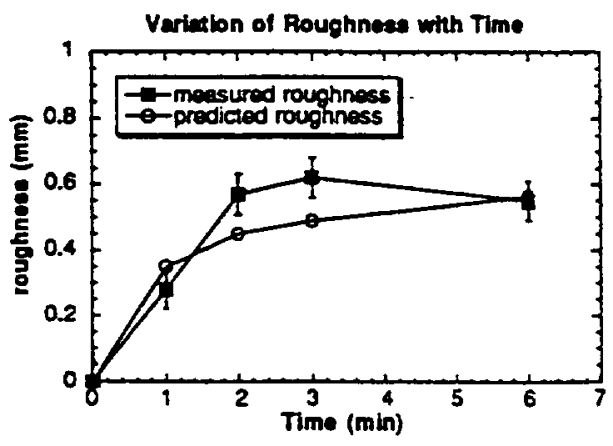

The variation of roughness with velocity is shown in Figure 7. The model shows excellent agreement with this parameter. This is an important result, as the previous model for sand-grain roughness predicted an increase in roughness, as shown by the dotted lines. The values are nearly constant over this range of conditions due to two competing effects in the theoretical model. The increase in velocity causes an increase in the amount of incoming water, which should increase the roughness. However, the higher velocity also causes a change in the flow derivative which results in a decrease in the roughness levels, especially near stagnation. The two effects cancel each other, causing essentially no change in roughness for these conditions.

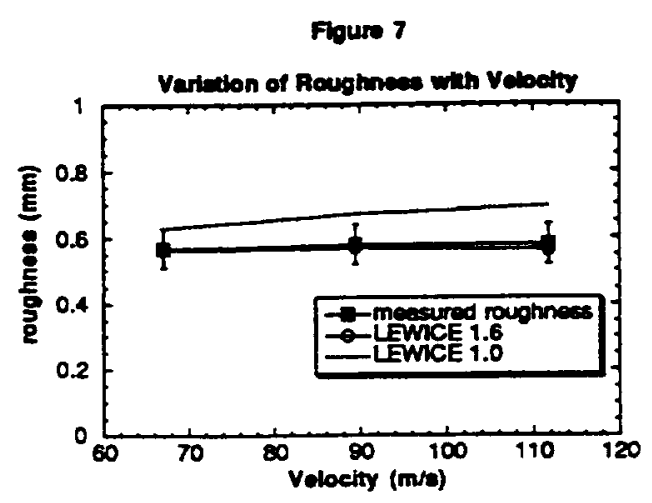

The effect of temperature on roughness is shown in Figure 8 . The roughness values predicted are reasonably close to the measured values, however the trend is opposite. The measured roughness increases very slightly with temperature, while the predicted levels show a minimum value at $28{ }^{\circ} \mathrm{F}$, with increased values at both ends, especially at the 25 of condition.

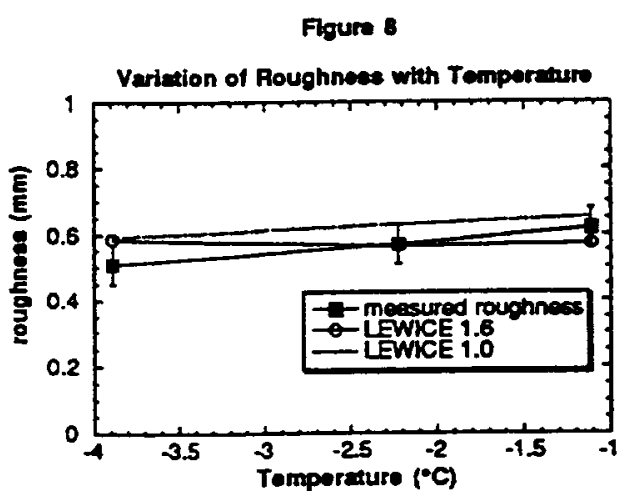

The increase in roughness from the $28^{\circ} \mathrm{F}$ case to the $30^{\circ} \mathrm{F}$ case is caused by a slight increase in surface tension with temperature. The increase in roughness from the $28^{\circ} \mathrm{F}$ case to the $25^{\circ} \mathrm{F}$ case is caused by a decrease in the wetting factor' which is caused by a change in the predicted contact angle of the roughness element. This theory needs to be developed further to correct the predicted trend. The 
current roughness prediction and the previous correlation are both within the experimental error over this range.

The variation of roughness with liquid water content (LWC) is shown in Figure 9. The roughness increases with LWC in both the predicted and measured values, but there is a significant $(20 \%)$ underprediction in roughness at the higher LWC values. However, this model is a vast improvement over previous models which predicted extremely high roughness values at high LWC, as shown by the dotted lines.

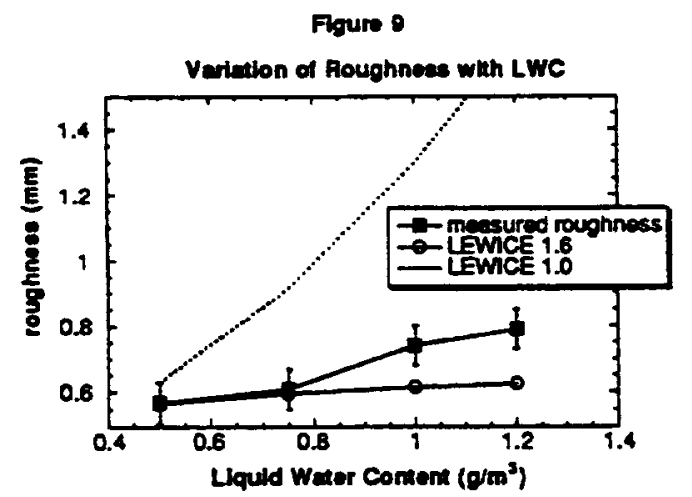

\section{Multi-Element Ice Accretion}

The Hess-Smith potential flow code used by LEWICE had the capability to predict flow on multielement configurations. Often, the limitations of potential flow make these predictions much less accurate than more sophisticated models, but it may be adequate for the purpose of providing sample ice shapes. However, the trajectory and ice accretion routines were only applicable for single element geometries. As a result of the current effort, not only can LEWICE periorm multi-element trajectories, but these routines can also be converted for use with more accurate flow solvers.

LEWICE performs multi-element trajectories by treating each element as a single entity. Impingement limits and collection efficiencies are determined on each body as though the other bodies are not there. Their influence on the trajectories is embedded in the flow solution, which takes into account all of the bodies. Any trajectory hits on other elements are treated as missed trajectories.
The hits on other bodies are, however, useful in determining the starting location of the next trajectory in the impingement limit search, especially hits on bodies which precede the one selected. For example, when the code looks for impingement limits on the flap(s), trajectory hits on the slat are useful in determining the starting bcation of the next trajectory. Routine MODE in LEWICE determines if a trajectory hits or misses a body. It was modified so that it not only knew that a body was hit, but which one. As stated earlier, hits on other bodies are only used to select the starting location of the next trajectory.

An additional problem occurs especially on the main element of a multi-element airfoil. It is possible for trajectories to hit this element by passing above the slat as well as by passing below the slat. Therefore, for all bodies but the first one (the slat) LEWICE will first look below the slat for an upper and lower impingement limit and determine one set of collection efficiencies for this set of impingement limits. LEWICE will then look above the slat and attempt to find a second set of impingement limits. If two sets of limits are found, the two collection efficiency arrays are merged.

This process is made clearer by looking at Figures 10 and 11. Figure 10 shows the two sets of impingement limits on the main element of a sample slat and main element combination. The collection efficiency curve for this condition is shown in Figure 11. Both bodies are NACA0012 airfoils. This is not a realistic test case, but is simply representative of the code's capabilities. If the user knows that impingement is going to occur on other elements by travelling below the slat, the user can bypass this option as the code will nu nearly twice as fast by bypassing this feature.

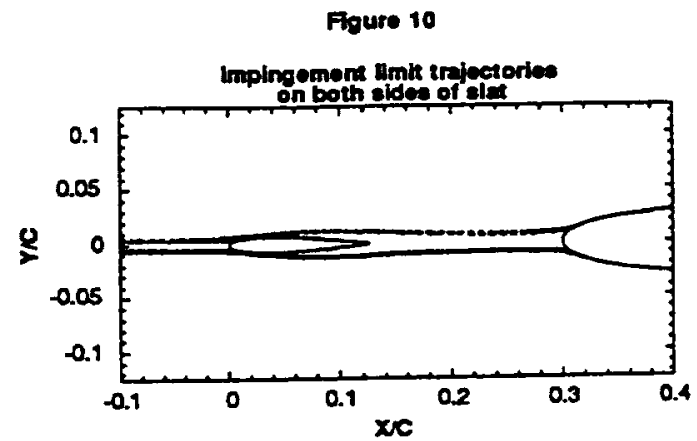




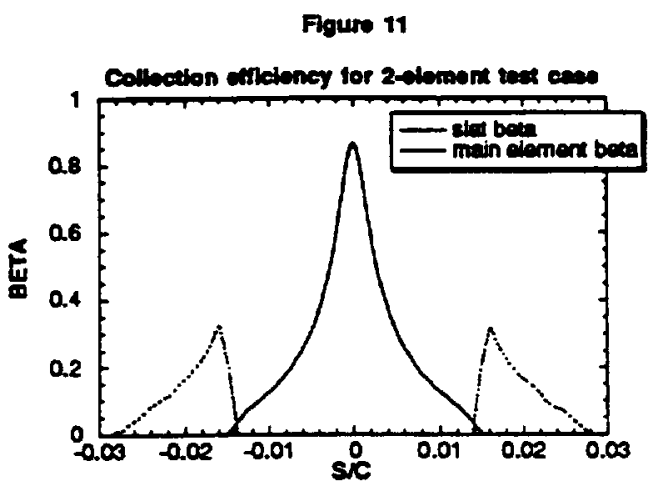

The process of converting LEWICE to handle multi-element geometries was made more difficult by the addition of the multiple geometry scheme used to increase the accuracy of the code. Atter the trajectory routine is completed, LEWICE creates a second set of panets for each element and resolves the flow field using this panel set. For a single element case, this second set of panels produces a smoother pressure distribution which increases the accuracy of the boundary layer integration. This is not always the case for multiple element geometries. Work is continuing on this routine so that this very useful feature can be used with multi-element geometries.

Once the collection efficiencies for each element has been found, and the flow recalculated, LEWICE is ready to perform the boundary layer integration and the ice accretion. Once again, this procedure is performed on each element individually, without regard to the presence or influence of other elements. The geometry modification is performed on each element individually, hence the code does not currently check for different elements intersecting due to ice growth. In this case, the code will most likely crash when it tries to solve the flow field on the next time step.

A comparison between this code and experimental data taken on a 5-element Boeing 737-200 airfoil. The airfoil is shown in Figure 12. The experimental data was taken in the IRT in 1991 and is documented in reference (4). The conditions for the comparison were:

$$
\begin{aligned}
& 15^{\circ} \text { flap } \\
& V=100 \mathrm{mph} \\
& T=28^{\circ} \mathrm{F}
\end{aligned}
$$

$$
\begin{aligned}
& L W C=0.92 \mathrm{~g} / \mathrm{m}^{3} \\
& M V D=14.4 \mu \mathrm{m} \\
& 0^{\circ} \text { angle of attack } \\
& \text { time }=8 \text { minutes }
\end{aligned}
$$

Figure 12

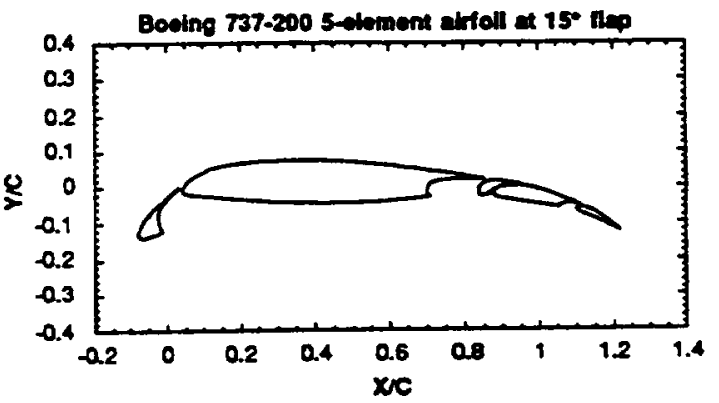

This case was selected because it was a glaze ice condition and ice was obtained on all five elements. The ice shape comparison is shown in Figs. 13-17. Due to the complex geometry, a Langmuir ' $D$ ' droplet distribution consisting of 7 drop sizes was used in the numerical prediction.

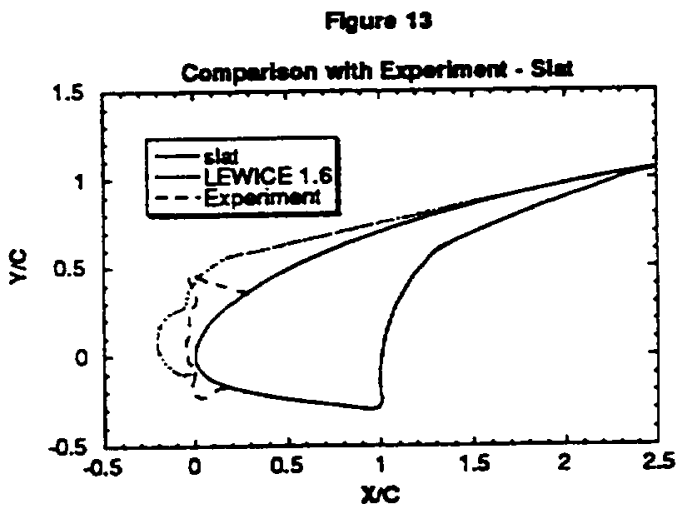

Foure 14

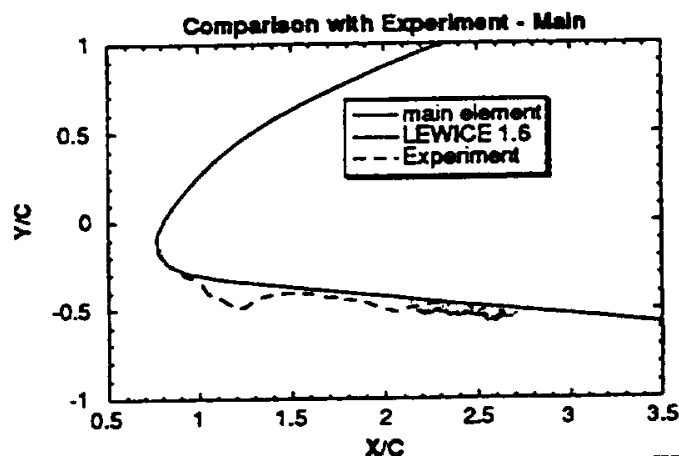


Figure 15

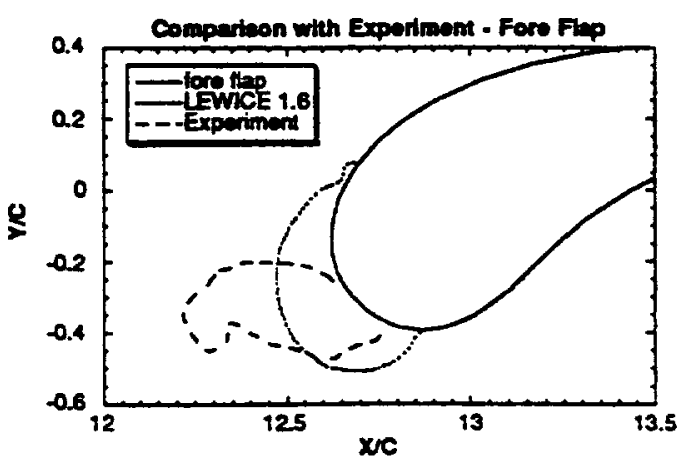

Foure 16

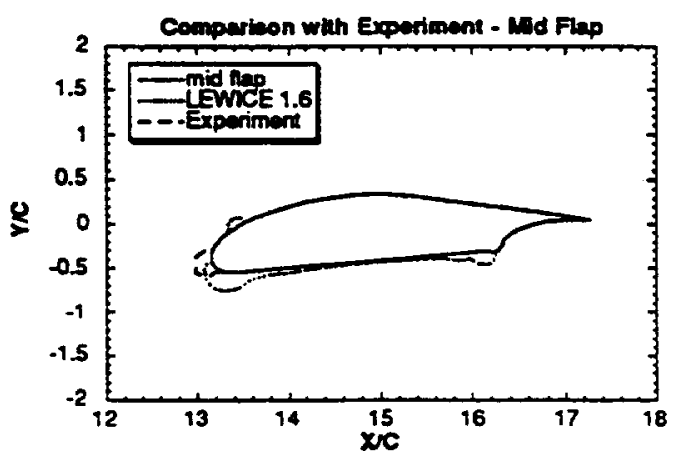

Fioure 17

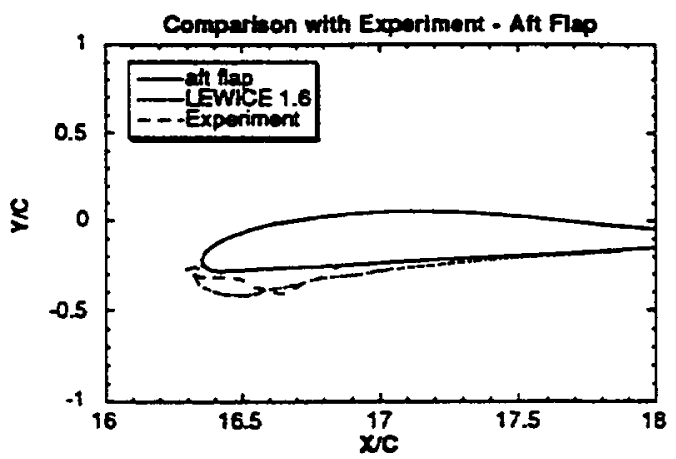

The predicted ice shape on the slat, shown in Figure 13 is representative of the very poor prediction when compared to the experimental data. This poor performance is somewhat surprising, as previous improvements to LEWICE had shown significant improvement in ice shape prediction for single element airfoils. The extent of predicted ice accretion in this figure is due to direct impingement, not due to extensive runback. This prediction is quite far from the experimental icing limits.

There are several reasons why this occurred. First, there are questions as to whether the configuration used in LEWICE is the same as the test configuration. Airfoil coordinates are only available in the stowed reference plane. A rotation angle, $x$-offset, and gap distance are listed in a table in the report which allows coordinates for the test configuration to be computed. However, the $15^{\circ}$ flap configuration is the only one of the three configurations for which the elements do not intersect with each other when this transformation is applied. This leaves open the question as to the validity of all of the numbers in the table, including this configuration. By observing pictures of the airfoil in the $15^{\circ}$ flap configuration, it is felt that the correct configuration was tested with LEWICE.

The second explanation for this discrepancy is the quality of the potential flow solution, which is plotted in Figure 18. The flow solution may not be adequate for this complex flow situation. A resolution of this question will not be known until more detailed analysis can be made with more accurate flow solvers.

Foure 18

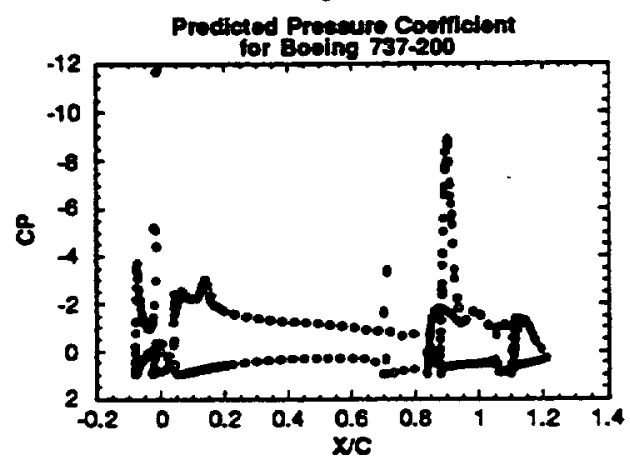




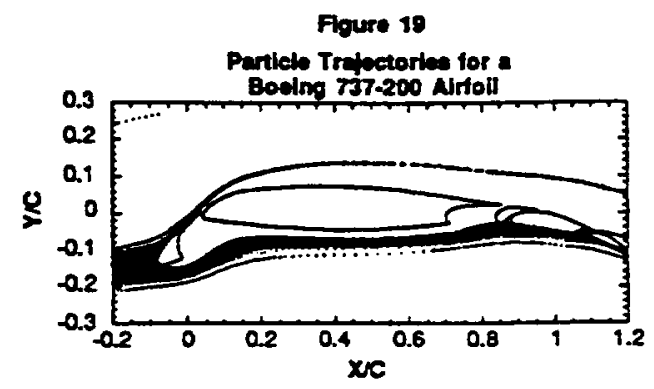

Finally, multiple time steps of this case were not possible due to errors within the code. Currently, only single time step ice shapes are possible for multi-element configurations until this issue is resolved. The changing iced geometry can change the collection efficiency distribution on a single element airfoil drastically and will no doubt have an impact on the results for this case.

The other elements also show major discrepancies between the predicted ice shape and the experimental ice shape. The ice shape for the main element is shown in Figure 14. In both the numerical and experimental shapes, a small amount of ice is produced just past the slat. The predicted shape is further down the chord than the experimental shape. This is consistent with the difference shown in the slat ice shapes. If the slat is raised slightly in space, more water will hit the main element and the impingement will be closer to the leading edge. It is unknown if this is due to errors in the flow or an error in the definition of the slat geometry.

The comparison for the fore flap is shown in Figure 15. The predicted impingement limits for this element are also much wider than the experimental shape. The prediction for this element would also be greatly improved if additional time steps could be ran. The prediction for the other two elements show the same trends. The prediction for the main flap, shown in Figure 16, shows some significant runback freezing. The upper surface shape is due to runback freezing and intersects the fore flap, meaning that the gap between them has filled with ice. This effect is one of the problems which must be dealt with for multi-time step runs to be nu. The comparison for the aft flap shows the same trends as described ear- lier and are likely due to accuracy of the flow solution and use of a single icing time step.

\section{Conclusions}

Three major improvements have been made to the LEWICE code. The LEWICE code has been modified to handle a large number of time steps for single element geometries and to perform the ice addition and recalculation of the flow accurately. A roughness model has been proposed which predicts measured roughness values much more accurately than previous models. Finally, multi-element trajectories and single time-step ice accretions on multi-element geometries are now possible.

Due to the ability of the code to handle a great number of time steps very accurately, little future work will be performed in this area due to the success of this routine. Work on the multi-element features is needed so that multiple time steps can be performed on these configurations as well.

The roughness prediction model shows much promise, but additional work is needed on a more robust model. Research is also being needed on the affect of this roughness on the heat transfer.

The code has shown the ability to predict collection efficiencies and single time-step ice accretions on multi-element geometries. Additional work is needed to extend this routine to multiple time steps and to make the solution more robust.

This new version of LEWICE is called LEWICE 1.6 (Beta) and is available for use by industry. Industry participants are forewarned that development of this code is continuing, especially for the multi-element features. For single element geometries, the code is working well. The multi-element option is still under development and may contain bugs' which have not yet been discovered. Care must be taken when using this option. Limited release of version 1.6 is recommended for multi-element users until these problems are resolved. The multi-element capability for LEWICE is considered a transitional code until these multi-element trajectory capabilities can be added to better multi-element flow codes. 


\section{References}

1) Rutt, G.A. and B.M. Berkowitz, "Users Manual for the NASA Lewis Ice Accretion Prediction Code (LEWICE)," NASA CR185129, May 1990.

2) Wright, W. B. , "Advancements in the LEWICE Ice Accretion Model," NASA CR191019 (AIAA-930171), Jan. 1993.

3) Shin, J. , "Characteristics of Surface Roughness Associated With Leading Edge Ice Accretion," NASA TM106459 (AlAA-94-0799), Jan. 1994.

4) Berkowitz, B.M., Potapczuk, M.G., Namdar, B.S. and Langhals, T.J. , "Experimental Ice Shape and Performance Characteristics for a Multi-Element Airfoil in the NASA Lewis lcing Research Tunnel," NASA TM105380, Dec. 1991.

5) Wright, W.B. , "Update to the NASA Lewis Ice Accretion Code LEWICE," NASA CR195387, Oct. 1994.

6) Al-Khalil, K.M. , "Numerical Simulation of an Aircraft Anti-lcing System Incorporating a Rivulet Model for the Runback Water," PhD Dissertation, University of Toledo, Toledo, Ohio, Jan. 1991. 

Public reporting bunden lor this collection of information is estimated to average 1 hour per response, including the time for reviewing instructions, searching existing data sources, gathering and maintaining the data needed, and completing and reviowing the collection of intormation. Send comments regarding Ins burden estinale or any orter aspect of this Davis Highway, Suite 1204, Arlington, VA 2202-4302, and to the Otfice of Management and Budget, Paperwork Reduction Project (0704-0188). Washington. DC 20503.

\begin{tabular}{|l|l|l|}
\hline 1. AGENCY USE ONLY (Leave blank) & $\begin{array}{c}\text { 2. REPORT DATE } \\
\text { March } 1995\end{array}$ & $\begin{array}{r}\text { 3. REPORT TYPE AND DATES COVEAED } \\
\text { Technical Memorandum }\end{array}$ \\
\hline
\end{tabular}

\section{TITLE AND SUBTTILE}

5. FUNDING NUMBERS

Additional Improvements to the NASA Lewis Ice Accretion Code LEWICE

6. AUTHOR(S)

WU-505-68-10

William B. Wright and Colin S. Bidwell

7. PERFORIMING ORGANIZATION NAME(S) AND ADDRESS(ES)

National Aeronautics and Space Administration

Lewis Research Center

Cleveland, Ohio 44135-3191

8. Performing organization REPORT NUMBER

E-9425

9. SPONSORINGMONITORING AGENCY NAME(S) AND ADDRESS(ES)

10. SPONSORINGMONITORING AGENCY REPORT NUMBER

National Aeronautics and Space Administration

Washington, D.C. 20546-0001

NASA TM-106849

AIAA-95-0752

11. SUPPLEMENTARY NOTES

Prepared for the 33rd Aerospace Sciences Meeting and Exhibit sponsored by the American Institute of Aeronautics and Astronautics, Reno, Nevada, January 9-12, 1995. William B. Wright, NYMA, Inc., Engineering Services Division, 2001 Aerospace Parkway, Brook Park, Ohio 44142 (work funded by NASA Contract NAS3-27186), and Colin S. Bidwell, NASA Lewis Research Center. Responsible person, Colin S. Bidwell, organization code 2720, (216) 433-3947.

12a. DISTRIBUTIONAVAILABILTYY STATEMENT

12b. DISTRIBUTION CODE

Unclassified - Unlimited

Subject Category 34

This publication is available from the NASA Center for Aerospace Information, (301) 621-0390.

13. ABSTRACT (Maximum 200 words)

Due to the feedback of the user community, three major features have been added to the NASA Lewis ice accretion code LEWICE. These features include: first, further improvements to the numerics of the code so that more time steps can be run and so that the code is more stable; second, inclusion and refinement of the roughness prediction model described in an earlier paper; third, inclusion of multi-element trajectory and ice accretion capabilities to LEWICE. This paper will describe each of these advancements in full and make comparisons with the experimental data available. Further refinement of these features and inclusion of additional features will be performed as more feedback is received.

\begin{tabular}{|c|c|}
\hline \multicolumn{2}{|l|}{ 14. SUBJECT TERMS } \\
\hline \multicolumn{2}{|c|}{$\begin{array}{l}\text { Ice accretion codes; Aircraft icing; Trajectory codes; Ice } \\
\text { Ice accretion prediction }\end{array}$} \\
\hline $\begin{array}{l}\text { 17. SECURTY CLASSIFICATION } \\
\text { OF REPORT }\end{array}$ & $\begin{array}{l}\text { 18. SECURTY CLASSIFICATION } \\
\text { OF THIS PAGE }\end{array}$ \\
\hline Unclassified & Unclassified \\
\hline
\end{tabular}
19. SECURITY CLASSIFICATION OF ABSTRACT Unclassified

15. NUMBER OF PAGES 14

16. PRICE CODE A03

20. LIMITATION OF ABSTRACT

Standard Form 298 (Rev. 2-89)

Prescrbed by ANSI Std. 239-18 298-102 